\title{
Quality culture of a faculty in a Vietnamese university
}

\author{
Pham Thi Huong ${ }^{1}$ \\ ${ }^{1}$ Institute of Education Research, Ho Chi Minh University of Education, Vietnam \\ *Corresponding author: phamhuong.mu@gmail.com
}

\begin{tabular}{|c|c|}
\hline ARTICLE INFO & ABSTRACT \\
\hline $\begin{array}{l}\text { DOI: 10.46223/HCMCOUJS. } \\
\text { soci.en.8.2.281.2018 }\end{array}$ & $\begin{array}{l}\text { Building a quality culture in each institution has been } \\
\text { encouraged by the Ministry of Education and Training (MoET) } \\
\text { along with the introduction of a new approach to higher } \\
\text { education, quality assurance and accreditation nearly } 15 \text { years } \\
\text { ago. This article attempts to report one case of a multiple case } \\
\text { study research that examines a quality culture in Vietnamese }\end{array}$ \\
\hline Received: October $23^{\text {rd }}, 2018$ & higher education. Data collection methods include \\
\hline evised: November $28^{\text {th }}, 2018$ & documentation and in-depth interviews with three groups of \\
\hline Accepted: December $6^{\text {th }}, 2018$ & $\begin{array}{l}\text { participants: academic leaders, academics, and quality assurance } \\
\text { (QA) staff. Data were analysed for patterns and themes. } \\
\text { Fourteen participants from a university volunteered to take part } \\
\text { in this research. The findings show that the faculty under } \\
\text { investigation traditionally assured higher education quality }\end{array}$ \\
\hline Keywords: & under a centralist mechanism. As a result, it has limited \\
\hline $\begin{array}{l}\text { higher education, quality } \\
\text { assurance and accreditation, } \\
\text { quality culture, Vietnamese } \\
\text { context }\end{array}$ & $\begin{array}{l}\text { autonomy and compliant accountability of limited bottom-up } \\
\text { engagement with decision-making processes. The faculty was } \\
\text { found to have characteristics of a reactive quality culture. }\end{array}$ \\
\hline
\end{tabular}

\section{Introduction}

Many authors have discussed widespread concerns about the quality of education provided by universities over the last two decades. This has necessitated the introduction of a new system of quality assurance. The new approach aims to evaluate higher education responses to changes, expenditure decisions, quality, and promoting student mobility (Kristoffersen \& Woodhouse, 2005). This has led to the development of various quality assurance (QA) policies and mechanisms. However, Harvey and Williams (2010) reviewed the QA development over the last fifteen years claiming that it remains unsure whether the standardisation and legalisation of QA are able to bring about an improvement on teaching and learning. On the one hand, external quality assurance approaches have not necessarily improved the student experience or transform quality at higher education level (Shah, 2012). Furthermore, academic communities perceived them as bureaucracy. They perceived their professional values in conflict with the QA agencies and governments, probably because external processes reflect the power of the agencies over the academic staff (T. H. Pham, 2014). On the other hand, Kristensen (2010) argued that external processes can help to improve the quality if welldeveloped internal quality systems were in place, or in other words, if the quality culture within individual institutions was developed along with external drivers. Recently, the concept of 
'quality culture' in higher education has been introduced more to express the idea that educational quality and culture of an organisation are not independent entities (Bendermacher, Egbrink, Wolfhagen, \& Dolmans, 2016); "quality stems from a broader cultural perspective" (Harvey \& Stensaker, 2008, p. 431).

\section{Quality culture in higher education}

For the study, the Quality Culture model (2006) by the European University Association (EUA) was applied as a theoretical framework (Figure 1).

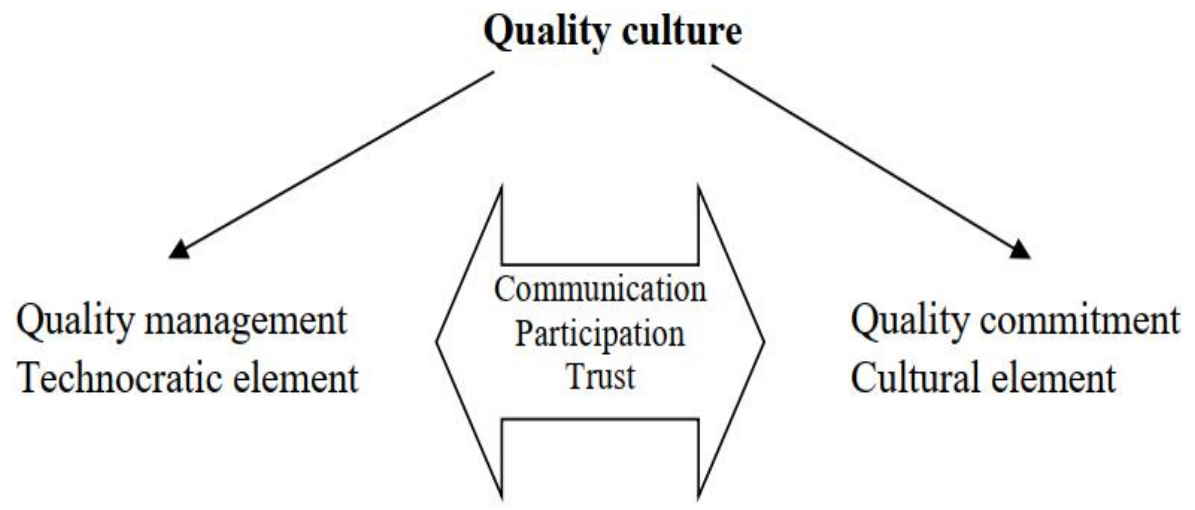

Tool and mechanisms to measure,

Individual level:

evaluate, assure, and enhance quality

personal commitment to strive for quality

Collective level:

individual attitudes add up to culture

Top-down

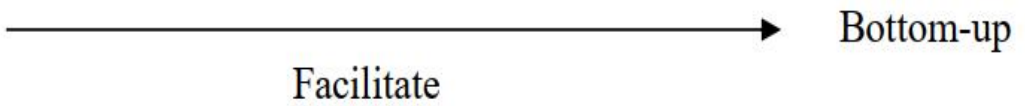

Activate Wind

Figure 1. Quality culture developed by the EUA (2006, p. 10)

The research also combined another approach examining the concept of quality culture in a "cultural theory framework" developed by Harvey and Stensaker (2008). They created four possible Weberian ideal-types of quality cultures (Table 1).

\section{Table 1}

Weberian ideal-types of quality cultures

\begin{tabular}{|l|l|l|}
\hline $\begin{array}{c}\text { Degree of group } \\
\text { control } \\
\begin{array}{c}\text { Intensity of external } \\
\text { rules }\end{array}\end{array}$ & Strong & Weak \\
\hline Strong & Responsive & Reactive \\
\hline Weak & Regenerative & Reproductive \\
\hline
\end{tabular}

Source: Harvey and Stensaker (2008, p. 436) 
In line with this theory, the quality culture of a faculty within a university in the Vietnamese context can be identified based on the level of individual's involvement in the quality assurance processes (Table 2).

\section{Table 2}

Explanation of the four quality cultures

\begin{tabular}{|c|c|c|c|}
\hline & & \multicolumn{2}{|c|}{ Degree of group control } \\
\hline & & Strong & Weak \\
\hline \multirow{2}{*}{ 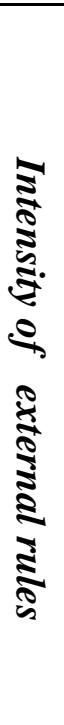 } & Strong & $\begin{array}{l}\text { Responsive quality culture: led } \\
\text { by external demands, } \\
\text { opportunistic, combining } \\
\text { accountability and } \\
\text { improvement, but perhaps also } \\
\text { sometimes a lack of ownership } \\
\text { and control }\end{array}$ & $\begin{array}{l}\text { Reactive quality culture: reward or } \\
\text { sanction led, task-oriented, doubts about } \\
\text { the potential of improvement, } \\
\text { compliance, reluctant ("beast to be fed") }\end{array}$ \\
\hline & Weak & $\begin{array}{l}\text { Regenerative quality culture: } \\
\text { internally oriented with a strong } \\
\text { belief in staff and existing } \\
\text { procedures, widespread, } \\
\text { experimental, although not } \\
\text { always adaptive to external } \\
\text { demands and developments }\end{array}$ & $\begin{array}{l}\text { Reproductive quality culture: wanting to } \\
\text { minimize the impact of external factors, } \\
\text { focusing on sub-units, and lack of } \\
\text { transparency throughout the institution, } \\
\text { emphasise the expertise of the } \\
\text { individual }\end{array}$ \\
\hline
\end{tabular}

Source: Adapted from Harvey and Stensaker (2008)

Harvey and Stensaker (2008) believed that this new approach was worth striving for its improvement potential. Lueger and Vettori (2008) concurred that a quality culture approach differs clearly from others, more traditional strategies to manage quality, particularly it focuses on development-oriented and value-based aspects. Therefore, the approach requires the involvement of all external and internal stakeholders, especially "front-line" academics and students, who are engaged with teaching and learning processes.

Improvement has been reported in Kowalkiewicz (2007)'s research in a Polish tertiary education institution. The study confirmed a strong positive correlation between the two variables: quality culture and quality of teaching. Quality culture largely determined the quality of teaching. Kowalkiewicz concluded that universities that placed a (relatively) lower value in their intellectual and material resources could be successful in improving quality through the development of quality culture.

Since its first official introduction in European universities, many authors have discussed the complexity of the concept of quality culture (Harvey \& Stensaker, 2008; Katiliute $\&$ Neverauskas, 2009). Most discussions have focused on the different theoretical frameworks 
and complicated nature of the issues, as well as literature around the two concepts, quality and culture, reflecting the possibility that many diverse efforts in building a quality culture are linked to transformative learning and teaching.

In Vietnam, considering quality culture as the final goal of recent efforts from the government and educational experts, it is necessary for developing understandings of quality culture at a particular faculty in a university.

\section{Methodology}

This study was undertaken as part of the research leading to a doctoral thesis. The study adopted a qualitative paradigm of fourteen participants from three groups of stakeholders such as academics, academic leaders, and QA staff.

Academic leaders were recruited as practitioners and managers of QA from the top. QA members are likely the individuals who could provide rich sources of information on quality management and assurance; therefore, they were also participants in this research. To ensure the maximum variation sampling (Patton, 2002), the number of QA members invited to join the research depending on the availability of these staff working at two levels: institutional and programmatic ones. Purposive sampling was applied at the university considering academics' genders, age and experience, and full time and part-time academics to ensure maximum variation sampling.

Nine academics, the dean of the Foreign Language Department (hereinafter called the dean), three QA staff members, and the head of the Office for Educational Testing and Quality Control (hereinafter called the head) ${ }^{1}$ participated in the study. The faculty provided programmes into Business English (BE) at both college and university levels ${ }^{2}$. The faculty was staffed by 12 full-time academics; one has a doctorate degree, seven have master's degrees, and four have bachelor's degrees. The number of visiting academics for the programme varied, ranging from 8 to 10 academics each semester. Both general English and English for specific purposes were taught to students who didn't major in English.

Interview questions which were developed based on the theoretical framework of the study cover two elements: quality management tools and mechanisms to assure quality at the faculty level and current practices by academics of the programmes as individual academics and as part of a faculty to commit to the quality of teaching and learning. The questions include mission and vision statements of the faculty, regulations to develop academic programmes, teaching and learning approach, academics and other staff recruitment, and student assessment and evaluation.

\footnotetext{
${ }^{1}$ Quotes from academics were coded as TT, academic leaders as AL, and QA staff members as QA. Letters A, $\mathrm{B}$, and $\mathrm{C}$ after these codes indicate quotes from University $\mathrm{A}, \mathrm{B}$, and $\mathrm{C}$ respectively. Numbers 1, 2, 3, 4, 5, 6, 7, 8 , and 9 at the end of each code were used to identify individual participants in each group of stakeholders. A code example is TTA1, which would denote a quote from a tertiary teacher no. 1 at University A

${ }^{2}$ College programmes are conducted in three years and university programmes in four years
} 


\section{Management of quality assurance and participants' perception}

\section{National programme framework}

The findings indicate that the dean designed the BE programme alone, based on the national programme framework for the English language, and he was trusted by the wider academic community at the faculty.

The dean confirmed his sole responsibility for designing the programme, noting that:

At the beginning of my deanship at the university, deans of various disciplinary departments were given autonomy to develop their programmes in conformity with the MoET's programme frameworks. The programme has to be approved by the university's scientific committee in consultation with the Academic Affairs Office, whose function is to find 'mistakes' of the programme based on the NPF. (ALA1)

This was reported by eight academics. Further description by the dean indicated that individual TEIs were required to abide by NPFs to develop their programmes. Four QA members shared similar information, perceiving that the national frameworks were "law" that must be observed. As the head said, "Compliance with the framework is compulsory because they have become "law"' (QAA4). If the university violated the framework, the MoET would decline to issue the resulting degrees.

This indicates the dominant role of the dean in the programme design. Other stakeholders including academics, students, alumni, and employers were made limited contributions to it.

Most academics indicated trust in the dean regarding programme design, textbook selection, and the selection of academics to teach courses, academics' limited input in these activities notwithstanding. One academic believed that the dean consulted experienced academics prior to designing the programme. Four academics trusted both the dean's ability to select suitable textbooks for the programme and his thoughtfulness in selecting academics to teach in the programme.

As regards the syllabus design, interviews with academics demonstrate that syllabus design was perceived to be one of the responsibilities of course academics, but not all programme courses had a syllabus. Four academics believed that those assigned to teach a course were accountable for designing a syllabus for the course, two of whom are quoted here:

Currently, it is assumed that who is selected to teach a course is responsible for designing the syllabus. (TTA4)

Academics are in charge of designing syllabi for their courses. It is unnecessary to require them to do that because syllabi are guidelines for them to teach. Extra and reference materials are of great importance to improve student levels. (TTA7)

In contrast, two academics disclosed that they did not write syllabi. One visiting academic developed a teaching plan, which she described as a timetable of teaching based on the table of contents of a required textbook. Academics further commented that no one checked or required them to submit syllabi. The dean claimed that "No academics wrote a syllabus" 
(ALA1), which appeared to indicate a tolerance of academics' responsibility for designing syllabi, or not designing one.

The underlying reason for the above practices of programme development is that the department appeared to develop some coping strategies to deal with national regulations. With a programme for MoET approval, course syllabi of a programme must be attached to the programme under examination. To respond to this requirement, the department designed syllabi in a token manner. Two academics recalled a story relating to syllabi design. One said:

Last year, the dean requested academics to write syllabi, but later he stopped it for some reasons. The dean used the syllabi he had written before. I just followed what he told me to do. I did not write any syllabus for my teaching. (TTA2)

The other observed this incident as a very sensitive issue, noting that during the time the university was being inspected, "documents and papers were created to deal with inspection" (TTA6). This explains the reason the dean requested academics to write syllabi, perhaps to provide evidence that programme courses had syllabi. The syllabi attached to the programme were not used in teaching.

In terms of academic autonomy, the department was believed to be not autonomous in designing programmes, leading to disagreement among the wider academic community and weaknesses that were believed to affect the quality of the programme. According to the dean, this was a result of compliance with the NPF or absence of sufficient autonomy:

The programme development has lacked democracy [autonomy] for ages. The department is required to follow the MoET's framework, which results in many difficulties. Our [Vietnamese] tertiary education is unpractical because the MoET decides everything. It sets a framework for each discipline. The framework is regarded as a type of law which TEIs are required to comply with. (ALA1)

As reported, the framework prevented the dean from changing the programme to address students' needs because of a mismatch between the available textbooks and the framework. He averred that segregated textbooks for BE were not available in the market, whereas the framework required four separate courses: Listening, Speaking, Reading, and Writing.

The second weakness involved a balance between the two stages of the programme. Academics noticed that students were required to study a range of 'political' courses, including Ho Chi Minh's Ideology, Leninism-Marxism, and other courses about physical and defence education at the general stage. This was perceived to result in a heavy study load. Consequently, less time was allocated for the professional stage. One academic put it in exactly those words: "There is insufficient time for the second stage" (TTA4).

\section{Hotpot programme, Business English or business in English?}

The programme was reportedly combined with three major components: the English language programme, inter-translation major, and BE. Three components were believed to conflict with each other: 
Studying business $[\mathrm{BE}]$, but students must study American-British literature. I am unsure - why do they have to study these courses? (TTA3)

They are students of business, but they have to study the 'too academic' [advanced] phonetics textbook. Academics need to adapt the book to match the student's level. (TTA1)

Three academics teaching in the professional stage perceived that students learnt everything about $\mathrm{BE}$, yet demonstrated a basic lack of expertise, naming a range of courses including English for Accounting, English for Foreign Trade, and English for Finance and Banking. They appeared to be in opposition to a list of courses designed for the professional stage. One academic thought students learnt courses of other disciplines: marketing and management. This perception was contradictory to the dean's intention in designing the programme. He said:

It is true that students currently study a little due to the name of the programme: BE. It is a broad term. The programme aims at providing students with basic concepts and access to materials related to BE. (ALA1)

The programme's objectives were perceived as vague and obscure by academics, who were confused as to whether the programme was a BE programme or a business programme taught in English media. One academic stated, "Students eventually study English only" (TTA4). Another academic expressed uncertainty about the major of the programme and about students' career prospects after graduation.

Further evidence from the interview data indicates that students' expectations of the programme were not always aligned with the programme's objectives. Three academics recalled their related conversations with students, reporting that students expected to learn $\mathrm{BE}$ instead of general English at the beginning of the programme, rather than at the second stage. This led to reported high drop-out rates during the general stage. One academic said:

Students are getting bored because they already studied general English elsewhere. (TTA1)

One academic believed that students "suffered" from studying in such an "absurd" programme as a result of the incongruous combination between the three components (TTA4). Consequently, most academics disclosed that their students were bewildered and very confused about their careers after graduation.

Yet, academics' perception of the programme's objective - that it be a business programme - differed to the predetermined objectives that required it to be more of a language programme. Limited involvement of academics in the programme development appeared to underpin the disparity. A lone dean could not anticipate the weaknesses of the programme identified by the wider academic community, and the programme failed to address student needs. 


\section{Programme review}

Academics viewed programme review as an update of textbooks with limited feedback from alumni and students. They noted that the dean had changed textbooks every three or four years. Four academics contributed to the update through informal talks with the dean. According to their views, the textbooks were published by famous publishers and, hence, reliable.

Theoretically, it is compulsory to organise regular professional meetings gathering deans, deputy dean, and heads of divisions to develop or review programmes for quality improvement. (TTA3)

Eight academics indicated uncertainty about any activities at the institutional level regarding student and alumni feedback, though they recalled a student survey in 2009 . The survey was perceived to be unsuccessful and was conducted as a coping strategy to meet the central requirements. Six academics were uncertain about the rationale for the survey. The dean complained that a number of questionnaire copies were left in the department, describing the survey as a waste of paper. Academics doubted the survey, stating that the results were not released. Three QA members and the dean explained this claiming that the university was unable to report on the survey as a result of inexperience and inability to analyse the data. According to one QA member, no computer software was used to analyse the data, and the data were put in manually so it disappeared later because of technical problems.

In summary, the update of textbooks was perceived as a significant activity for a programme review at the departmental level. Alumni feedback was collected at the institutional level but was seen as ineffective and done in a formalistic manner, so was the student survey. According to the academics' perspective, student feedback was not collected to review the programme. Academics regarded complaints relating to academics' performance during class time as a type of feedback, which was not always addressed.

\section{Academic commitment to teaching}

Academic commitment to teaching was believed to determine the quality of their lessons. Commitment was defined as associated with academics' professional knowledge and teaching methodologies, with particular emphasis on those that enhanced student learning and empowered students to learn. Commitment was also believed to be associated with academics' proactive roles in professional development to enable them to teach better, to understand students' needs, and to adjust their teaching methods to match the students' ability and level.

The dean classified two types of academics in terms of their commitment to teaching. The first was perceived to complete what was required to do. The academics of this group were restricted to use the required textbooks to teach without referencing other materials. The other type was perceived to spend more time preparing lessons and using a range of materials to complement the required textbooks.

Two full-time academics significantly believed that visiting academic staff were less committed to and less well prepared for teaching. They reported that several visiting academics 
received complaints from students. Three reasons were articulated for the lesser commitment of visiting academic staff: (a) ineffective measures to evaluate their teaching, (b) their status as "guests" at the university, and (c) the result of low salary. In contrast, two visiting academics believed that they accomplished their tasks. According to one, her responsibility was to teach the assigned courses effectively, and she was unaware of other activities of the university. The other believed she had the same commitment to all classes she was responsible for, irrespective of her position at a university: either a full-time or visiting academic.

The findings demonstrate that academics, both full-time and visiting, shared a common belief that they determined the quality of every lesson they delivered, depending upon professionalism and commitment, irrespective of some signs of discrimination between fulltime and visiting academics in terms of their commitment to teaching. Limited evidence was found to establish a perceived link between academics' status and the quality of their teaching performance, as one academic shared:

The quality of a course depends on individual academics, not on their status. Who commits to teaching will invest their courses and teaching more. The dean will not check on their performance. (TTA4)

The following section explores academics' perceptions and reasoning of their choice of the teaching profession in relation to their commitment to teaching.

\section{Academic commitment to research}

Research activities were reported as being significantly limited and weak at the institutional level by QA members and as being minimal at the department level by academics. Research activities at the university were restricted to the establishment of a research office, raising academics' awareness of a need to conduct research, and launching a scientific magazine. It was reported that most articles in the magazine were written by deans and heads, and young and new academics were found to have a limited contribution to the magazine.

Research was added as a criterion to emulate academics at the department in 2011. Despite the policy, academics reported a limited research output at the department. Two academics noticed that the dean once mentioned the need for research, but they believed that no further actions had been taken to inspire academics to conduct research. Most academics interviewed indicated the reluctance to spending time and effort on research without a robust appraisal scheme.

The emulating scheme at the institution failed to stimulate academics to do research due to the perceived absence of recognition and financial benefits. Discussing the impact of the new policy on emulating academics, the dean stated that he would regard syllabus writing and "compiling" textbooks (copying from different sources to create a textbook for internal use) as research activities as a last resort for his academics. As he said, "These are 'exits' for academics at the department" (ALA1). Based on these dumbed down criteria, three academics were recommended to be titled "emulation fighters" in 2011. They were, however, not approved by the university because there was no evidence showing that they conducted research. 
Academics did not share a common understanding of what research entails. Three academics believed in the research-teaching nexus that research enabled academics to teach better. Others who debated teaching and researching were integrated processes because academics were responsible for investigating student needs and choosing suitable methods to teach. This was believed to be underway informally during teach largely because of the perceived limited time available to do it formally (TTA5). Reading articles related to their concerns was viewed as a way to improve teaching and was also perceived to research. Six academics regarded research in the English language (a foreign language) with English teaching methodologies and approaches. One said, "Research in the English language is something that methodologists studies...like language teaching methodologies, such as audio-visual or communicative approaches....

They wrote books on methodologies which we use in teaching" (TTA4). Expanding on this, another academic noted, "Our duty is to apply the language teaching methodologies effectively. You are really good if you can do that" (TTA5). Two academics perceived research as studies about issues and problems in classrooms. One expressed her view as below:

Research? It seems too big for me. I personally think that each academic is doing research while teaching, investigating student attitudes and appropriate methodologies for a class. That is research. Indeed, I think research is simple like that. Every academic can do research on how to enhance student learning. (TTA5)

Significantly, five interviewees including academics and QA members mentioned "copy and paste" research. They regarded this type of research as a way to "tick the box" (TTA4). They believed these studies were "superficial and useless" (QAA3) or "easy to do" (TTA4). Consequently, they had no intention of doing research as such.

These perceptions of research likely explain limited research outputs at the institution and at the department. English major per se was first identified as a constraint to research outputs at the department:

There are no directions for us to do research in the language in general... We are required to do research, but what we can do for a language! ... I feel quite difficult and ... limited. Research in the English language that can be applied in reality is very limited; finding something practical is an issue, rather than there is nothing to research. (TTA7)

In contrast, the dean believed that the position of the department affected the reported limited research outputs. The department was the only social humanities department in an economics university, leading to the perceived shortage of qualified academics to form a committee to review research proposals, which was believed to be a major obstacle. He negated the perception from his academics that the English language per se was the reason, noting that:

Other TEIs have a variety of topics for language research. These topics are in line with their majors, such as Applied Linguistics or TESOL... In case of our university, who will become judges or supervisors if there is any research? (ALA1) 
Another reason for limited research outputs was restricted time for research. Due to the reported rapid expansion of student enrolments, academic staff were required to teach more classes; doing research, as a result, was too difficult alongside such expansion:

It is obvious that due to rapid expansion, all TEIs have to undergo a similar trend that they do not have sufficient academics to teach. Research is impossible to accompany that rapid expansion. (QAA4)

[The department] forces academics to have many classes, how can they find time for research? (TTA4)

Limited time for research was also a result of moonlighting due to low salary. Academic staff indicated an intention to take more classes for extra income. Two academics believed they could not afford their life with their current salaries. As a result, they had to teach "in and out," especially at English language centres. Further, academics considered teaching to be paid better than research:

Doing research is paid less. That is why academics mainly teach. Having extra classes, academics can earn more money. Consequently, they spend most of their time teaching and have no time for research. The two reasons both exist in reality. (TTA4)

Limited research outputs were also identified to be a result of limited research competence. Two academics perceived themselves to be unqualified to carry out research:

I only did a small project for my master's thesis. The topic is about mistakes that Vietnamese students make in pronunciation; it is for my degree only. I shared it with my friends. It is not available for the public to read and use as a reference. I am not at that level. (TTA5)

Tolerance of non-adherence to the policy that required academics to do research was also viewed as contributing to limited research activities at the department. Research was stipulated to be a major responsibility of academics by the MoET, yet it was not clear what would happen if this responsibility was not met:

Though it is said that research is one of the responsibilities of academics, and people all know that they cannot be evaluated as fulfilling their tasks without doing research, it is flexible in reality. There are no sticks. That is what is enacted but in reality ....it is flexible: All are classified as fulfilling their tasks, [even if they did not carry out research]. (TTA6)

For visiting academics, they mentioned that the department did not require them to research:

I am a visiting academic, and then I do not need to do research for the department. (TTA9)

In summary, academics perceived that their commitment to teaching determined teaching quality. According to their perspectives, commitment to teaching involved professional knowledge and pedagogical competence that enabled student to learn. Drives for this commitment were closely linked to altruistic desires to become academics with their own reputation respected by their colleagues and students. Academics' commitment to research was 
found to be minimal as regards the research outputs at the department and was restricted to exploring student needs informally, or reading materials to improve professional knowledge. The appraisal scheme for research was perceived as having limited impacts on informing academics' commitment to teaching and research.

\section{Compliance with the MoET's requirement for student assessment}

Compliance with the MoET's requirement concerning training and evaluating students, Regulation No. 25, was found at the institutional level. A review of the regulation indicates that it prescribed full-time tertiary education programmes in terms of training, checking and examining units of study, graduation examination, and recognition for full-time tertiary education students. At the department, academics' perceptions of the regulation were limited to two types of assessing student performance: mid-term assessments (30\% of final scores) and final course assessments (70\%). The Academic Affairs Office, as reported by QA members, was in charge of implementing the rest of the regulation for the entire university.

\section{Academic autonomy and equity}

Academics averred that their autonomy in assessing students substantially and procedurally, but it was found to result in variety and sometimes conflicted perceptions of student assessment at the department.

Academics were divided into their perspectives on mid-term assessment and assessment strategies. As regards the mid-term assessment, two academics highlighted the importance of assessing student progress authentically (within the process of learning) because of the belief that the mid-term scores of students at the department did not reflect their actual ability:

Progress assessment was conducted inaccurately, completely inaccurate! (TTA3)

Some academics graded students with high scores for mid-term tests. For example, one academic marked almost 9 and 10 for a writing course. I rarely mark students with such high scores. (TTA5)

In contrast, other academics viewed mid-term assessment as a method to encourage students to be in attendance and to promote student autonomy:

Student assessment is incumbent on academics. Student learning attitude, for me, is worth $30 \%$ and $70 \%$ for knowledge. Because $30 \%$ is evaluated based on student learning attitudes, academics and students can negotiate how to assess this, including attendance and other assessment strategies. Seventy percent is assessed based on final course examinations. (TTA6)

The grading process was considered as intuitive and unfair. Professional knowledge of the individual academics for the test, especially regarding the level of difficulty, which was seen as a result of the perceived absence of shared academic standards in assessing students. A widespread evaluation policy that academics applied in the department was to test student memory. This, as perceived, failed to enhance student's learning because students forgot 
everything immediately after examinations. This policy also did not encourage students' creativity and critical thinking.

Academics' status was discussed as contributing to disparities in testing in terms of "seriousness" in marking. Visiting academics believed to mark "generously" to capture students' hearts. As the dean said:

One visiting academic graded 10 for a student's internship report. When I read the report, I am so disappointed with the paper. I have to re-mark it. (ALA1)

Another academic recalled that she was surprised when she saw one list of students' scores marked by a visiting academic; that most students received 9 and 10. According to her, this was unbelievable (unacceptable) because she knew the students' ability (she taught the same class).

In summary, linkages were found between perceived academic autonomy and the reported inequity due to the absence of a shared view on and discussion about academic standards for student assessment. Little evidence was found of benchmarks shared between academics that might not encourage equity, validity, and reliability; nor were measures found to align student assessment with the course's objectives.

\section{Discussion centralism, autonomy, and accountability}

The findings of this study support the observation by Hayden and Lam (2007) that tertiary education in Vietnam has a highly centralised control system for management and governance. The relationship between the government and universities in Vietnam is top down and one way. Therefore, TEIs are granted limited autonomy in both forms suggested by Berdahl (1990): substantive and procedural autonomy.

University A did not have the freedom to steer themselves in terms of institutional autonomy as defined by Askling, Bauer, and Marton (1999). For example, TEIs in Vietnam rely heavily on MoET's annual enrolment quota (Tran, Nguyen, \& Nguyen, 2011). This lack of autonomy is also due to the MoET's role in determining programmes which (Tran et al., 2011) referred to as "close-to-absolute power." The institution was not granted full autonomy for designing their programmes. Standardisation underlies the promulgation of the national framework across the nation.

The centrally imposed obligation could only promote a culture that developed coping strategies for compliance, rather than improvement at the local level. At University A, the dean wrote syllabi for all courses of the programme for central inspection. Recently, the framework had been repealed an attempt to grant substantive autonomy to TEIs. Although the abolishment of the framework in principle ensures the possibility that individual institutions may take this opportunity to reform programmes, there is little hope for an authentic reform because the two national universities who had been granted such autonomy did not take that opportunity (Hayden \& Lam, 2010). This has resulted in "a type of regulated autonomy... that they were still 'dancing in a cage' even though their shackles have been removed" (Yang, Vidovich, \& Currie, 2007, p. 590). Substantive autonomy is not sufficient for a university. 
The highly centralised system has inhibited procedural autonomy at the institution, leading to the reported compliance found in this research. Sometimes, to avoid a situation of "blame and shame" (Coy, 2011), the institution developed coping strategies to preserve the reputations of involved parties.

The institution reported compliance with the NPF and the national regulations to assess students and to emulate staff. Academics' requests and suggestions tended to be ignored due to the complexity of changing what had been approved by the central government. Centralism allows limited space for contextualisation; therefore grassroots' voices were not heard. This inability to be heard has shaped 'uncaring' attitudes to quality issues among academics at University A. This risks the loss of imagination and commitment of academic staff in teaching (Karpiak, 2000).

This centralism and lack of autonomy have led to problematic accountability at tertiary education in Vietnam. T. N. Pham (2010) believes that lack of accountability has made the centralism in Vietnam outmoded and extremely conservative. Under the state control systems, accountability in Vietnamese tertiary education is input-focused, intrusive, and rigid (Raza, 2010). At University A, several participants claimed that there was no 'quality' to assure because they had to conform to the central requirements irrespective of whether or not they were relevant. TEIs are often not willing to be accountable for what is designed and planned centrally (Jamil, 2008). As Jamil argued, "It is neither realistic nor fair to expect tertiary education institutions that enjoy limited autonomy to be fully accountable for their performance" (p. 9). Harvey (2004-2005) in his website defines accountability in tertiary education as "the requirement, when undertaking an activity, to expressly address the concerns, requirements or perspectives of others." It is likely that compliance is what the three institutions were doing under centralism. This echoes what (Harvey \& Newton, 2007) noted, that "accountability is an inclusive phrase for various compliance, control and value-for-money expectations" (p. 230).

\section{At individual level}

This section examines the individual academic autonomy and accountability regarding teaching, student assessment, and research under the state-control system in Vietnam. According to Berdahl (1990), "academic freedom is that freedom of the individual scholar in his/her teaching and research to pursue truth wherever it seems to lead without fear of punishment or termination of employment for having offended some political, religious or social orthodoxy" (pp. 171-172). Altbach (2001) identified that restrictions on academic freedom in some countries, including Vietnam, are mainly about the fields that are considered politically or ideologically sensitive. Political and ideological topics were not part of the focus of this research. Contrary to limited autonomy and problematic accountability at the institutional level, academics at the three departments were autonomous in teaching, research, and student assessment. Nevertheless, the autonomy granted to academics in teaching and student assessment varied at the three institutions. 
The academics at Universities A were given the choice of whether or not to use the required textbooks. This freedom allowed their necessary adaptations to improve their classroom situations. The autonomy of academics in student assessment at Universities A indicated large disparities that could not be solely attributed to individual academics' perceptions of how to assess students, but was probably based on textbooks and their own criteria and competence at translating their goals for assessment of tests. The reported assessment practice at tertiary level in Vietnam is perhaps situated in a condition that Davidson et al. (2009) described as an amalgam of academic tradition and mixed understandings of the purposes of assessment, leading to the considerable disparity. Consequently, academics may benefit from some standardisations of testing and assessment, perhaps to protect them from being classified as strict academics, which might lead to low grading from students. The expectation for standardisation is also aimed at ensuring equity in assessment.

Yet autonomy in assessment requires consistency and equity which was claimed to be problematic at the university. The promulgation of the national standards for quality accreditation had not changed traditional methods to assess quality at any of the three institutions, and nor, evidently, had it improved quality. It then becomes necessary to question the purpose of the national standards, whether they are developed as an additional bureaucratic tool or a strategy for fostering the central power of the government.

Restrictions on academics' autonomy in the research were not reported in this research. This echoes Altbach (2001) who observed that in Vietnam, participation in international scientific and scholarly networks is not restricted but actively encouraged. The findings indicate that research was minimally inhibited by the government, but limited research was conducted at the department. Teaching and research are among key areas requiring changes and innovations for quality improvement in the tertiary sector in Vietnam (HERA, 2006).

The findings of this research illustrate that any initiatives to improving teaching emanated from academics' willingness and aspirations to reflect on their teaching on a daily basis through observing their classroom atmospheres, talking to students frequently, and sometimes collecting student feedback. This process of improving teaching practices could be augmented by encouraging academics to demonstrate accountability: making explicit their theories of teaching (Hendry \& Dean, 2002) or "more explicit regarding their [academics'] aims and the methods they use to achieve them" (Ellis, 1993, p. 240). This quest for accountability could possibly avoid complacency in individual academics about their teaching performance, as claimed by an academic that her colleagues from her department were 'free' from the inspection after the probationary period or the widespread complaint that good or bad teaching performance would not affect academics' tenure. Harvey and Newton (2007), however, noted that something that is regulated in such a manner would not enable improvement. Instead, improvement can occur through critical engagement. It appears unnecessary to require academics to be explicitly accountable for their teaching quality. Research-led teaching, collegial working environments, and authentic engagement in the academics activities of the academic community could be various forms of critical engagement, which promise an improvement of student learning and experience. 


\section{Reactive quality culture}

According to a quality culture in a cultural theory framework developed by Harvey and Stensaker (2008) they identified a quality culture of an institution, the three universities were characterised by features of a reactive quality culture (Figure 2). Based on the features indicative of a quality culture suggested by Harvey and Stensaker (2008) and the characteristics of a reactive quality culture identified by Jonach, Gramlinger, and Hartl (2012), the findings of this study suggest following features of the reactive quality culture at the university.

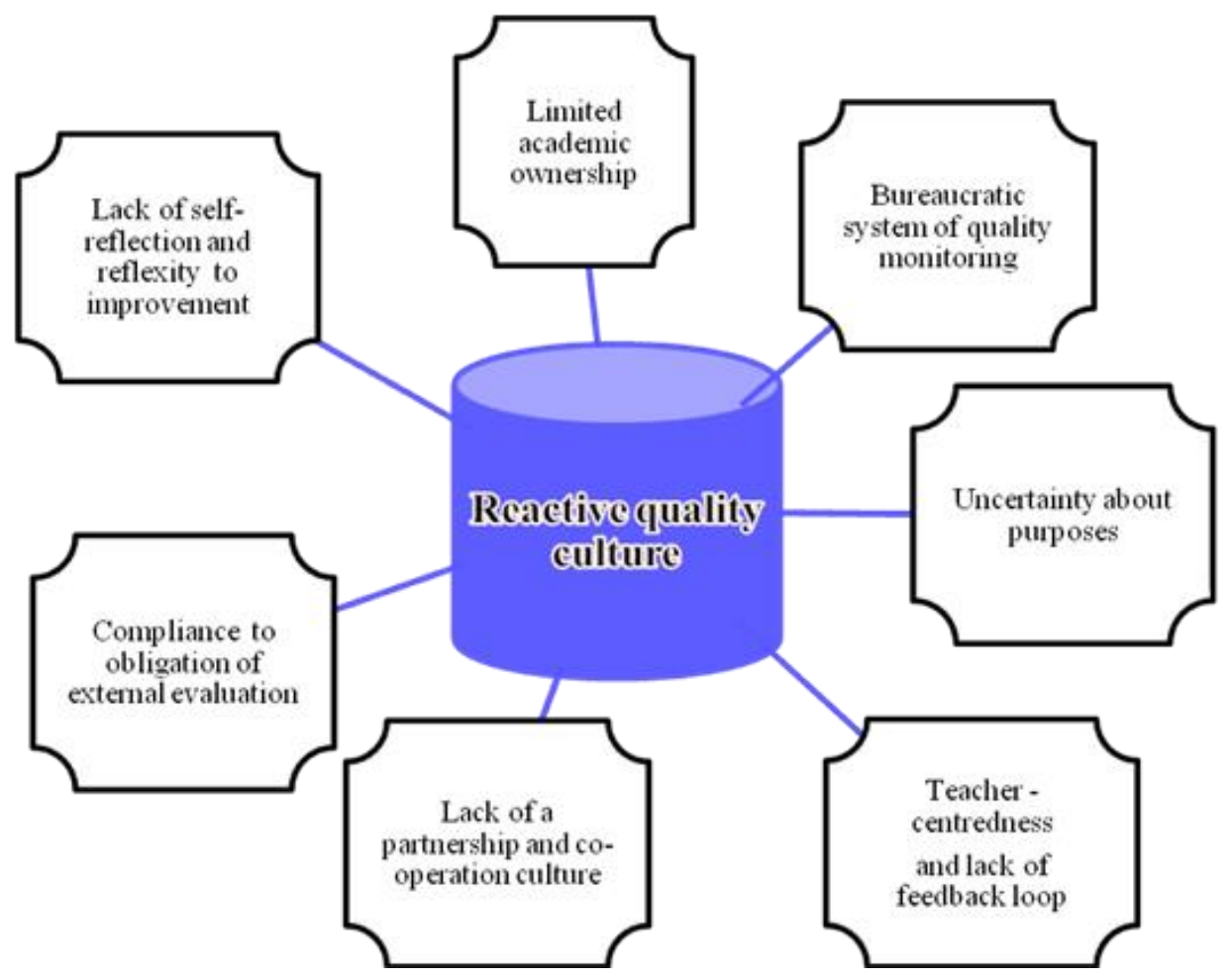

Figure 2. Characteristics of reactive quality culture at University A

\section{Conclusion}

For the university to develop a successful quality culture, a key role in such a change would be the middle management (deans and heads of programmes) who are able to link and connect top-down and the bottom-up approaches. Academic leaders are currently in a position to discuss the central requirements, regulations, and policies comprehensively with the wider academic communities and other grassroots stakeholder groups to resolve challenges of complying with the central demands, instead of blaming the centralised system for not matching their contexts. They are also the group who could promote the participation of people at the grassroots level to engage actively in conversations about how to improve the quality of teaching and learning. For the Department of Foreign Languages at the university, the role of middle management is crucial to ensure that the bottom-up participation does not challenge the power and reputation of people at higher positions, nor does it shorten the power distance between the boss and the subordinates. At the grassroots level, quality assurance in Vietnam could be expanded to include a critique and feedback from students if the process is designed 
to be culturally appropriate. Individual steps and activities to build a self-critical and reflective academic community should involve no shame and blame so that the development of a quality culture results in a culture of improvement.

Academic leaders, particularly the dean and head of BE programmes, must be proactive in engaging the wider academic communities at their departments in decision-making about academic issues including programme development and review. They also play a vital role in organising academic activities to promote professional development including creating a supportive working environment for the wider academic communities, developing shared testing and assessment strategies, and supporting academics to conduct research. This research indicated that without academic input in developing their programmes, academics were opposed to the objectives predetermined by the deans and the heads, and often unaware of the objectives, which lead to varied interpretations of the objectives: were they teaching in a business or language programme? This research also demonstrated that academic involvement in the programme design and course syllabi created a sense of ownership to the involved activities, which echoes Truong (2013) who found teachers' involvement in a decision-making process that increased the quality of decisions and motivating subordinates' responsibility. The future governance of tertiary education at institutional and departmental levels requires a new approach to accommodate academic input into the decision-making processes, as suggested by Harloe and Perry (2004).

\section{References}

Altbach, P. G. (2001). Academic freedom: International realities and challenges. Higher Education, 41(1), 205-219.

Askling, B., Bauer, M., \& Marton, S. (1999). Swedish universities towards self-regulation: A new look at institutional autonomy. Tertiary Education and Management, 5(2), 175-195.

Bendermacher, G. W. G., Egbrink, M. G. A. o., Wolfhagen, I. H. A. P., \& Dolmans, D. H. J. M. (2016). Unravelling quality culture in higher education: A realist review. The International Journal of Higher Education Research, 73(1), 39-60. doi: 10.1007/s 10734015-9979-2

Berdahl, R. (1990). Academic freedom, autonomy and accountability in British universities. Studies in Higher Education, 15(2), 169-180.

Bolander, K., Josephson, A., Mann, S., \& Lonka, K. (2006). Teachers promoting expertise in medical education: Understanding the role of the core curriculum. Quality in Higher Education, 12(1), 41-55.

Colbeck, C. (1998). Merging in a seamless blend. Journal of Higher Education, 69(6), 647671.

Coy, M. (2011). Putting quality at the centre of quality assurance - Where is the centre? Paper presented at the 6th European Quality Assurance Forum, Belgium. 
Davidson, S., Anderson, H., Rees, M., McKenzie, L., Johnston, T., Fletcher, R., \& Meyer, L. (2009). An investigation of assessment policy and practice in New Zealand higher education institutions. In L. Meyer, S. Davidson, H. Anderson, R. Fletcher, P. Johnston \& M. Rees (Eds.), Tertiary assessment and higher education student outcomes: Policy, practice and research (pp. 65-76). Wellington, New Zealand: Ako Aotearoa.

Doring, A. (2002). Challenges to the academic role of change agent. Journal of Further and Higher Education, 26, 139-148.

Dunrong, B. (2007). Shifting demographics in higher education in Asia. International Higher Education, 47, 14-15.

Ellis, R. (1993). The management of quality in the University of Ulster. Higher Education, 25, 239-257.

EUA. (2006). Quality culture in european universities: A bottom-up approach. Retrieved May 15 , 2018, from http://www.eua.be/eua/jsp/en/upload/Quality_Culture_2002_2003.1150459570109.pdf

Harloe, M., \& Perry, B. (2004). Rethinking or hollowing out the university? External engagement and internal transformation in the knowledge economy. Paper presented at the the OECD Institutional Management in Higher Education General Conference, Paris.

Harvey, L. (2004-2005). Analytic quality glossary. Retrieved October 20, 2017, from http://www.qualityresearchinternational.com/glossary/

Harvey, L., \& Newton, J. (2007). Transforming quality evaluation: Moving on. In D. Westerheijden, B. Stensaker \& M. J. Rosa (Eds.), Quality assurance in higher education: Trends in regulation, translation and transformation (pp. 225-245). Amsterdam, Netherlands: Springer.

Harvey, L., \& Stensaker, B. (2008). Quality culture: Understandings, boundaries and linkages. European Journal of Education, 43(4), 427-442.

Harvey, L., \& Williams, J. (2010). Fifteen years of quality in higher education. Quality in Higher Education, 16(1), 3-36. doi:10.1080/13538321003679457

Hayden, M., \& Lam, Q. T. (2007). Institutional autonomy for higher education in Vietnam. Higher Education Research \& Development, 26(1), 73-85. doi:10.1080/07294360601166828

Hayden, M., \& Lam, Q. T. (2010). Vietnam's higher education system. In P. T. Nghi, G. Harman \& M. Hayden (Eds.), Reforming higher education in Vietnam: Challenges and priorities (pp. 15-30). Amsterdam, Netherlands: Spinger.

Hendry, G. D., \& Dean, S. J. (2002). Accountability, evaluation of teaching and expertise in higher education. The Internarial Journal of Academic Development, 7(1), 75-82.

Houston, D., Meyer, L. H., \& Paewai, S. (2006). Academic staff workloads and job satisfaction: Expectations and values in academe. Journal of Higher Education Policy and Management, 28(1), 17-30. 
Jamil, S. (2008). The growing accountability agenda: Progress or mixed blessing? Paper presented at the OECD ${ }^{\text {ee }}$ s Outcomes of Higher Education: Quality, relevance and impact Conference, Paris, France.

Jenkins, A., Breen, R., Lindsay, R., \& Brew, A. (2003). Reshaping teaching in higher education: Linking teaching and research. London \& Sterling: Kogan Page.

Jonach, M., Gramlinger, F., \& Hartl, S. (2012). Quality needs culture: The quality culture concept and its applicability in the context of (vocational) schools. Retrieved October 22, 2017, from website: www.bwpat.de.

Karpiak, I. (2000). The 'second call': Faculty renewal and recommitment at midlife. Quality in Higher Education, 6(2), 125-134.

Katiliute, E., \& Neverauskas, B. (2009). Development of quality culture in the universities. Economics \& Management, 14, 1069-1076.

Kowalkiewicz, A. (2007). The impact of quality culture on quality of teaching - A case of business higher education in Poland. In L. Bollaert et. al (Eds.), Embedding quality culture in higher education: A selection of papers from the 1st European Forum for quality assurance (pp. 63-68). Brussels: European University Association.

Kristensen, B. (2010). Has external quality assurance actually improved quality in higher education over the course of 20 years of the 'quality' revolution? Quality in Higher Education, 16(2), 153-157.

Kristoffersen, D., \& Woodhouse, D. (2005). An overview of world issues in quality assurance for higher education. AUQA website: Australian Universities Quality Agency. Retrieved October 25, 2017, from http://www.auqa.edu.au/qualityenhancement/publications/other

Lueger, M., \& Vettori, O. (2008). "Flexibilising" standards? The role of quality standards within a participative quality culture. In: A. E. Beso (Ed.), Implementing and using quality assurance: Strategy and practice (pp. 11-16). Brussels: EUA.

Meyer, L. H. (2007). Collegial participation in university governance: A case study of institutional change. Studies in Higher Education, 32(2), 225-235.

NCIHE. (1997). Higher education in the learning society: Report of the national committee of enquiry into higher education (the Dearing Report). London, UK: HMSO.

Patton, M. Q. (2002). Qualitative evaluation and research methods (3rd ed.). Newbury Park, CA: Sage Publications.

Pham, T. H. (2014). Quality culture in Vietnamese universities: A multiple case study of quality assurance and quality culture of business English undergraduate programmes at three universities in Vietnam. (Doctoral dissertation, Victoria University of Wellington, New Zealand).

Pham, T. N. (2010). The higher education reform agenda: A vision for 2020. In G. Harman, M. Hayden \& T. N. Pham (Eds.), Reforming higher education in Vietnam (pp. 51-64). Amsterdam, Netherlands: Springer. 
Ramsden, P., \& Moses, I. (1992). Associations between research and teaching in Australian higher education. Higher Education, 23(3), 273-295.

Raza, R. (2010). Higher education governance in East Asia. Washington, DC: World Bank Flagship.

Shah, M. (2012). Ten years of external quality audit in Australia: Evaluating its effectiveness and success. Assessment \& Evaluation in Higher Education, 37(6), 761-772.

Shin, J. C. (2015). Mass higher education and its challenges for rapidly growing East Asian higher education. In J. C. Shin, G. A. Postiglione \& F. T. Huang (Eds.), Mass higher education development in East Asia: Strategy, quality, and challenge (pp. 1-23). Switzerland: Springer.

The World Bank. (2000). Higher education in developing countries: Peril and promise. Washington, DC: World Bank Group.

Thompson-Whiteside, S. (2013). Assessing academic standards in Australian higher education. In S. Marginson (Ed.), Tertiary education policy in Australia (pp. 39-58). Melbourne, Australia: Centre for the Study of Higher Education

Tran, N. D., Nguyen, T. T., \& Nguyen, M. T. N. (2011). The standard of quality for HEIs in Vietnam: A step in the right direction? Quality Assurance in Education, 19(2), 130-140.

Truong, D. T. (2013). Confucian values and school leadership in Vietnam (Doctoral dissertation). Victoria University of Wellington, New Zealand.

Welsh, J. F., \& Metcalf, J. (2003). Administrative support for institutional effectiveness activities: Responses to the 'new accountability'. Journal of Higher Education Policy and Management, 25, 183-193.

Yang, R., Vidovich, L., \& Currie, J. (2007). "Dancing in a cage": Changing autonomy in Chinese higher education. Higher Education, 54, 575-592. doi:10.1007/s10734-0069009-5

Yorke, M. (2000). A cloistered virtue? Pedagogical research and policy in UK higher education. Higher Education Quarterly, 54(2), 106-126. 